\title{
Double ipsilateral parathyroid adenomas, with one supernumerary and ectopic at the same time: a case report
}

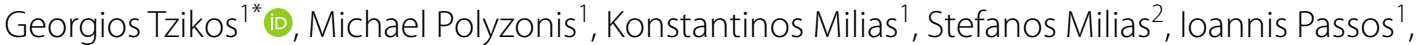 \\ Konstantinos loannidis ${ }^{1}$, Nektaria-Dimitra Doutsini ${ }^{3}$, Georgios Chatzoulis ${ }^{1}$ and Panagiotis Spyridopoulos ${ }^{1 \wedge}$
}

\begin{abstract}
Background: Double adenomas (DA) represents a distinct clinical entity of primary hyperparathyroidism (PHPT). DA may follow various embryologic distribution patterns and could be supernumerary and/or ectopic.

Case presentation: We describe the first case of PHPT which comes as a result of double ipsilateral adenoma, of which one was both ectopic and supernumerary. A 45 year-old Greek male patient with diagnosed PHPT due to a single lower right parathyroid adenoma was admitted to our department for surgical treatment. The preoperative tests (neck US, Sestamibi scan) were conclusive for single gland disease. The patient underwent focused parathyroidectomy. The frozen section revealed a parathyroid adenoma with a slight possibility for parathyroid carcinoma. Ten minutes after the excision, intact PTH (iPTH) dropped $>50 \%$ related to preoperative values and was within normal range. Right hemithyroidectomy with additional ipsilateral central neck dissection was performed, because of the possibility for parathyroid carcinoma. The final pathology report showed that the first excised tissue proved to be a parathyroid adenoma, while a second subcapsular one and a normal right upper parathyroid gland were also found.

Conclusions: Preoperative localization of DA using routine imaging tests and the utility of intraoperative parathyroid hormone assay are still unreliable in detecting multiple adenomas. Furthermore, a slight possibility of a second and simultaneously supernumerary and ectopic adenoma maybe present. Therefore, it would be advisable to establish the use of more advanced imaging tests (such as 4D-CT, 4D-MRI) or other diagnostic tools when DA are suspected.
\end{abstract}

Keywords: Primary hyperparathyroidism, Double adenoma, Ectopic, Supernumerary, Case report

\section{Background}

Primary hyperparathyroidism (PHPT) is a common endocrine disorder. It is estimated that 100,000 new cases emerge every year in the United States of America. PHPT is characterized by excessive secretion of parathyroid hormone $(\mathrm{PTH})$, causing calcium and phosphate

\footnotetext{
*Correspondence: tzikos_giorgos@outlook.com

${ }^{\wedge}$ Panagiotis Spyridopoulos deceased before the publication of this work was completed

1 1st Surgical Department, 424 General Military Hospital, Ring Road, 56429 EfkarpiaThessaloniki, Greece

Full list of author information is available at the end of the article
}

abnormalities. The majority of PHPT cases are due to solitary benign adenoma (85-90\%), while less frequently (15-20\%) by either multiple adenomas or hyperplasia and rarely due to parathyroid carcinoma (1\%) [1-3]. In recent years, there is a growing consensus that double adenomas (DA) represent a distinct clinical entity and should not be confused with an asynchronous type of four-gland hyperplasia. It is reported that the incidence of DA is up to $15 \%$ of all PHPT patients [4-7].

Ectopic or supernumerary parathyroid glands arise due to abnormal migration of parathyroid cells from the $3^{\text {rd }}$ and $4^{\text {th }}$ branchial pouches to their final position. Moreover, the incidence of one (or more) ectopic parathyroid original author(s) and the source, provide a link to the Creative Commons licence, and indicate if changes were made. The images or other third party material in this article are included in the article's Creative Commons licence, unless indicated otherwise in a credit line to the material. If material is not included in the article's Creative Commons licence and your intended use is not permitted by statutory regulation or exceeds the permitted use, you will need to obtain permission directly from the copyright holder. To view a copy of this licence, visit http://creativecommons.org/licenses/by/4.0/. The Creative Commons Public Domain Dedication waiver (http://creativeco mmons.org/publicdomain/zero/1.0/) applies to the data made available in this article, unless otherwise stated in a credit line to the data. 
adenoma(s) is between 6 and 16\%, while the incidence of a supernumerary parathyroid adenoma is even lower, about 5\% [8-10]. However, the incidence of an ectopic and supernumerary hyperfunctioning gland is only about $0.69 \%$ [11]. Milas et al. in their investigation of 127 patients with DAs found little prevalence of coexistence of DA with supernumerary or ectopic parathyroid gland though normal (4 and 3 out of 127 patients, respectively) [7]. Herein, we present the first case of PHPT due to ipsilateral DA, in which one was both ectopic and supernumerary.

\section{Case presentation}

A 45 year-old Greek male with PHPT admitted to our department for parathyroidectomy due to diagnosed PHPT caused by benign parathyroid adenoma. The patient was an Officer in Hellenic Air Force, married without children. On admission, he reported fatigue as the only symptom he experienced and the vital signs were normal (blood pressure: $135 / 65 \mathrm{mmHg}$, heart rate: 72 pulses/min, temperature: $36.8{ }^{\circ} \mathrm{C}$ ). Our findings during the physical examination were the following: 1 . head: eyes, nose, mouth, ears were normal, 2. neck: without any swelling area and trachea in the central position, 3. anterior torso: thorax and abdomen without abnormalities during observation, normal breath sounds, normal heart sounds and normal abdominal sounds, 4. posterior torso: without any spinal curvature or lung deformity, 5. pelvic and rectal examination: normal, 6. upper and lower extremities: without any abnormalities. Moreover, the results of our neurological examination were: 1 . normal mental status, 2. cranial nerves evaluation: normal findings, 3. normal reflexes, 4. motor function and balance: normal findings, 5 . sensory examination: normal findings, 6. coordination examination: normal findings. His medical history was free and there was not any family history for hypercalcemia or multiple endocrine neoplasia syndromes. The patient was not taking any medication before diagnosis. Besides, no allergies were reported and the patient did not smoke or consume alcohol. Laboratory tests revealed a serum total calcium of $2.8 \mathrm{mmol} / \mathrm{l}$ (normal range $2.05-2.55 \mathrm{mmol} / \mathrm{l}$ ) with an elevated PTH of $204.70 \mathrm{pg} / \mathrm{ml}$ (normal range 15.00-68.30 $\mathrm{pg} / \mathrm{ml}$ ). Serum phosphate was $3.2 \mathrm{mg} / \mathrm{dl}$ (normal range: $2.5-4.5 \mathrm{mg} / \mathrm{dl}$ ), 25 hydroxyvitamin-D level was $27.2 \mathrm{ng} /$ $\mathrm{ml}$ (normal range: $20-50 \mathrm{ng} / \mathrm{ml}$ ) and 24-h urine calcium level was $202.1 \mathrm{mg} / 24 \mathrm{~h}$ (normal range: 100-300 $\mathrm{mg} / 24 \mathrm{~h}$ ). Thyroid function tests were normal. The detailed laboratory results are reported in Table 1. Neck ultrasound revealed that the thyroid gland had normal dimensions and there was an inferior right-sided $23 \times 11$ x $13 \mathrm{~mm}$ extrathyroid nodule, indicative of parathyroid adenoma (Fig. 1). Furthermore, the patient underwent ${ }^{99 \mathrm{~m}} \mathrm{Tc}-$ Sestamibi scintigraphy (MIBI) and the result was in accordance with the neck ultrasound (Fig. 2). Under the diagnosis of PHPT and with a CaPTHUS score of 4 [Intact PTH level $\geq 2$ times upper limit of normal PTH level, Sestamibi scan results positive for 1 enlarged parathyroid gland, Neck ultrasound results positive for 1 enlarged thyroid gland and concordant sestamibi and neck ultrasound study results (identifying 1 enlarged gland on the same side of the neck)] indicative for single gland disease, the patient was admitted for focused parathyroidectomy [12]. However, intraoperatively, we did not find any parathyroid gland at the lower pole of the right thyroid lobe. Therefore, we continued with a right neck exploration and only a normal parathyroid gland was recognized on the superior right pole of the thyroid. Thus, we decided to proceed on exploring the left side of the neck which revealed two normal parathyroid glands. Nevertheless, after repeated attempts to discover the pathologic right parathyroid gland, we noticed a small bulging at the right lower thyroid pole (Fig. 3: blue arrow) suspicious for an intrathyroidal parathyroid adenoma. Prior to the attempt to dissect this bulging, we finally found an enlarged nodule, morphologically similar to parathyroid adenoma. This was at the right side of the neck in connection with the carotid sheath, far away from the thyroid gland [Type $\mathrm{C}$ based on the nomenclature of parathyroid classification (Table 2) [13], which was excised and sent for frozen section (Fig. 4). Ten minutes after the excision of the suspected adenoma, a blood sample was taken and the intact PTH level dropped and was within normal range $(49.30 \mathrm{pg} / \mathrm{ml})$, indicating a reduction of more than $50 \%$ from the preoperative level. The frozen section report showed a "parathyroid neoplasm, with a low possibility of parathyroid carcinoma, due to the presence of fibrous bands". Based on these findings, we decided to perform right hemithyroidectomy with additional ipsilateral central neck dissection (Fig. 3). In the immediate postoperative period and until discharge, paracetamol (1000 mg, four times per day), nonsteroidal anti-inflammatory drugs (lornoxicam $4 \mathrm{mg}$, twice per day) and omeprazole (20 mg, twice per day) were administered intravenously. The patient received and tolerated well liquid and solid food six hours after the procedure. In the first postoperative day, serum calcium, phosphate and PTH levels were $2.175 \mathrm{mmol} / \mathrm{l}, 1.04 \mathrm{mmol} / \mathrm{l}$ (normal range: $0.74-1.52 \mathrm{mmol} / \mathrm{L}$ ) and $45.80 \mathrm{pg} / \mathrm{ml}$ respectively. The patient discharged without any complications, in the second postoperative day. To our surprise, the final pathology report revealed that: (1) the first dissected "parathyroid neoplasm" was a parathyroid adenoma and not a carcinoma, with $2.7 \mathrm{~cm}$ maximum diameter, (2) 
Table 1 Patient's laboratory results on admission

\begin{tabular}{|c|c|c|}
\hline Test & Value & Normal values \\
\hline \multicolumn{3}{|l|}{ Complete Blood Count } \\
\hline Hematocrit & $45.4 \%$ & $42.0-54.0 \%$ \\
\hline Hemoglobin & $15.0 \mathrm{gr} / \mathrm{dl}$ & $13.0-18 \mathrm{gr} / \mathrm{dl}$ \\
\hline Red Blood Cell Count & $5.18 \mathrm{M} / \mathrm{ml}$ & $4.5-5.5 \mathrm{M} / \mathrm{ml}$ \\
\hline Mean Corpuscular Volume (MCV) & $87.6 \mathrm{fl}$ & $78.0-98.0 \mathrm{fl}$ \\
\hline Mean Corpuscular Hemoglobin (MCH) & $29.0 \mathrm{pg}$ & $27.0-31.0 \mathrm{pg}$ \\
\hline Mean Corpuscular Hemoglobin Concentration (MCHC) & $33.0 \mathrm{gr} / \mathrm{dl}$ & $32.0-36.0 \mathrm{gr} / \mathrm{dl}$ \\
\hline Red Blood Cell Distribution Width (RDW-CV) & $13.3 \%$ & $11.5-14.0 \%$ \\
\hline White Blood Cell Count & $6.2 \mathrm{~K} / \mu \mathrm{L}$ & $4.0-11.0 \mathrm{~K} / \mu \mathrm{L}$ \\
\hline Neutrophils & $62.0 \%$ & $40.0-70.0 \%$ \\
\hline Platelet Count & $307 \mathrm{~K} / \mu \mathrm{L}$ & $142-450 \mathrm{~K} / \mu \mathrm{L}$ \\
\hline \multicolumn{3}{|l|}{ Biochemical tests } \\
\hline Serum glucose & $114 \mathrm{mg} / \mathrm{dl}$ & $70-105 \mathrm{mg} / \mathrm{dl}$ \\
\hline Serum urea & $39.00 \mathrm{mg} / \mathrm{dl}$ & $19.00-44.00 \mathrm{mg} / \mathrm{dl}$ \\
\hline Serum creatinine & $0.82 \mathrm{mg} / \mathrm{dl}$ & $0.72-1.25 \mathrm{mg} / \mathrm{dl}$ \\
\hline Aspartate transaminase (AST) & $17.0 \mathrm{U} / \mathrm{L}$ & $5.0-34.0 \mathrm{U} / \mathrm{L}$ \\
\hline Alanine transaminase (ALT) & $30.0 \mathrm{U} / \mathrm{L}$ & $00.0-55.0 \mathrm{U} / \mathrm{L}$ \\
\hline Gamma-glutamyl Transferase & $20.0 \mathrm{U} / \mathrm{L}$ & $12.0-64.0 \mathrm{U} / \mathrm{L}$ \\
\hline Alkaline phosphatase (ALP) & $70 \mathrm{U} / \mathrm{L}$ & $40-150 \mathrm{U} / \mathrm{L}$ \\
\hline Lactate dehydrogenase (LDH) & $170 \mathrm{U} / \mathrm{L}$ & $125-220 \mathrm{U} / \mathrm{L}$ \\
\hline Serum potassium & $4.5 \mathrm{mmol} / \mathrm{L}$ & $3.4-5.1 \mathrm{mmol} / \mathrm{L}$ \\
\hline Serum sodium & $140.2 \mathrm{mmol} / \mathrm{L}$ & $136.0-145.0 \mathrm{mmol} / \mathrm{L}$ \\
\hline Triiodothyronine (T3) & $1.2 \mathrm{ng} / \mathrm{ml}$ & $0.6-1.6 \mathrm{ng} / \mathrm{ml}$ \\
\hline Thyroxine (T4) & $6.73 \mu \mathrm{g} / \mathrm{dl}$ & $4.87-11.72 \mu \mathrm{g} / \mathrm{dl}$ \\
\hline Thyroid Stimulating Hormone (TSH) & $1.33 \mu \mathrm{lU} / \mathrm{ml}$ & $0.35-4.94 \mu \mathrm{lU} / \mathrm{ml}$ \\
\hline \multicolumn{3}{|l|}{ Serology } \\
\hline Surface antigen of the hepatitis B virus ( $\mathrm{HBs} A g$ ) & $0.19 \mathrm{~S} / \mathrm{CO}$ & Negative $<1.00 \mathrm{~S} / \mathrm{CO}$ \\
\hline Hepatitis C Virus test & $0.07 \mathrm{~S} / \mathrm{CO}$ & Negative $<1.00 \mathrm{~S} / \mathrm{CO}$ \\
\hline $\mathrm{HIV} \mathrm{Ag} / \mathrm{Ab}$ & $0.12 \mathrm{~S} / \mathrm{CO}$ & Negative $<1.00 \mathrm{~S} / \mathrm{CO}$ \\
\hline \multicolumn{3}{|l|}{ Coagulation tests } \\
\hline Activated Partial Thromboplastin Time (aPTT) & $34.7 \mathrm{~s}$ & $25.0-45.0 \mathrm{~s}$ \\
\hline Prothrombin Time (PT) & $11.31 \mathrm{~s}$ & $12.00-14.00 \mathrm{~s}$ \\
\hline International Normalized Ratio (I.N.R.) & $0.951 .00-1.50$ & \\
\hline
\end{tabular}

\%: percent; gr/dl: grammar per decilitre; $\mathrm{M} / \mathrm{ml}$; millions per milliliter; fl: femtolitres; pg: picogrammars; $\mathrm{K} / \mu \mathrm{L}$ : thousands per microlitre; $\mathrm{U} / \mathrm{L}$ : Units per litre; $\mathrm{mmol} / \mathrm{L}$ : millimoles per litre; $\mathrm{ng} / \mathrm{ml}$ : nanograms per millilitre; $\mu \mathrm{g} / \mathrm{dL}$ : micrograms per decilitre; $\mu \mathrm{lU} / \mathrm{ml}$ : milli-international units per millilitre; $\mathrm{S} / \mathrm{CO}$ : signal/cut-off; s: seconds

there was one smaller subcapsular parathyroid adenoma, with $1.1 \mathrm{~cm}$ maximum diameter, located at the lower pole of the right thyroid lobe (Fig. 5) and (3) a normal parathyroid gland was found at the inferior border of the right central neck dissection specimen. Finally, eighteen months after surgery, patient's serum calcium, serum phosphate and PTH levels were still within normal range ( $2.425 \mathrm{mmol} / \mathrm{l}, 1.06 \mathrm{mmol} / \mathrm{l}$ and $55.0 \mathrm{pg} / \mathrm{ml}$ respectively), confirming a successful, curative parathyroidectomy for PHPT. Furthermore, the patient did not report any symptom and physical and neurological examination did not reveal any pathological signs.

\section{Discussion}

In our study, we present the first described case of PHPT due to ipsilateral DA of which one was both ectopic and supernumerary and the other was subcapsular. We are demonstrating that DA represent a true discreet clinical entity which can contribute in difficulties or pitfalls concerning the management and the surgical plan of patients with PHPT. Although a lot of work has been done in order to identify the pathogenesis of adenomas and the difference between them and parathyroid hyperplasia, it is still controversial if adenomas arise only by clonal or 


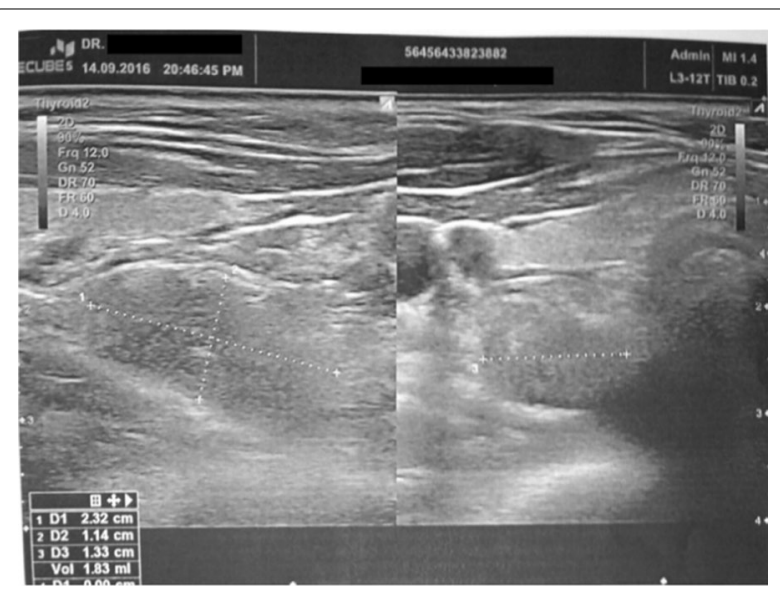

Fig. 1 Thyroid ultrasound revealing an inferior right-sided nodule, indicative of parathyroid adenoma

also by polyclonal mechanism, even if most adenomas are of monoclonal proliferation [14]. However, it is clinically proven that DA represent a unique clinical setting and should be distinguished from hyperplasia. Medical literature report that there is a high long-term cure rate after two-adenoma resection in patients with PHPT, which is the best evidence of DA as a separate disease [4]. Moreover, a greater awareness of this entity among surgeons and a wider use of intraoperative parathyroid hormone assay (ioPTH) which helps in finding the adenoma and terminating the operation, have driven in a continuous rise of its initial prevalence, as high as $15 \%$ in recent studies [7].

Regarding the distribution of double parathyroid adenomas, it seems that they have a nonuniform pattern as Milas et al. observed in their study, although it was found that superior-bilateral DA were statistically more frequent (45\%). Regarding the ipsilateral right DA, only 11 out of 127 (9\%) patients had this configuration, although both adenomas were found to be orthotopic [7]. Similarly, Abboud et al. also found that DA can be identified in all possible configurations, with bilateral distribution being the most dominant [15]. Nevertheless, in our patient the distribution of DA was ipsilateral, even though one was ectopic. The inferior parathyroid glands arise from the 3rd branchial pouch and during their migration to their final orthotopic location, a number of factors, yet unknown, may affect their movement, contributing to the genesis of ectopic parathyroid tissue. In this case, our theory is that the parathyroid tissue of the 3rd pouch on the right, might have the tendency to evolve into a parathyroid adenoma. In addition, there has been an abnormal transportation of the parathyroid tissue of the 3rd pouch on the right, which resulted initially in its division, giving birth to the 5th parathyroid gland, and then in the migration of one of these two glands in an ectopic

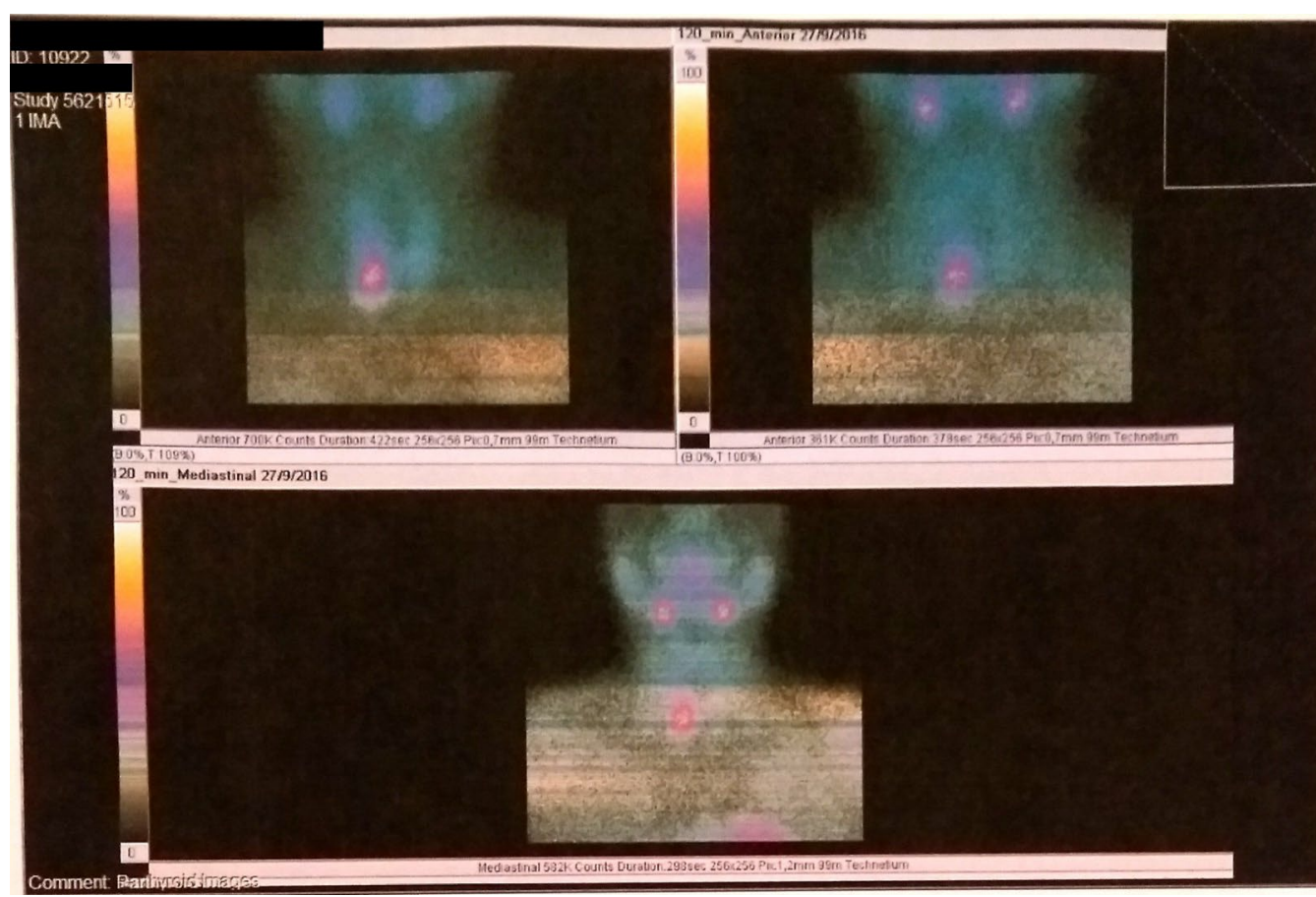

Fig. 2 99mTc-Sestamibi scintigraphy revealing an inferior right-sided parathyroid adenoma 


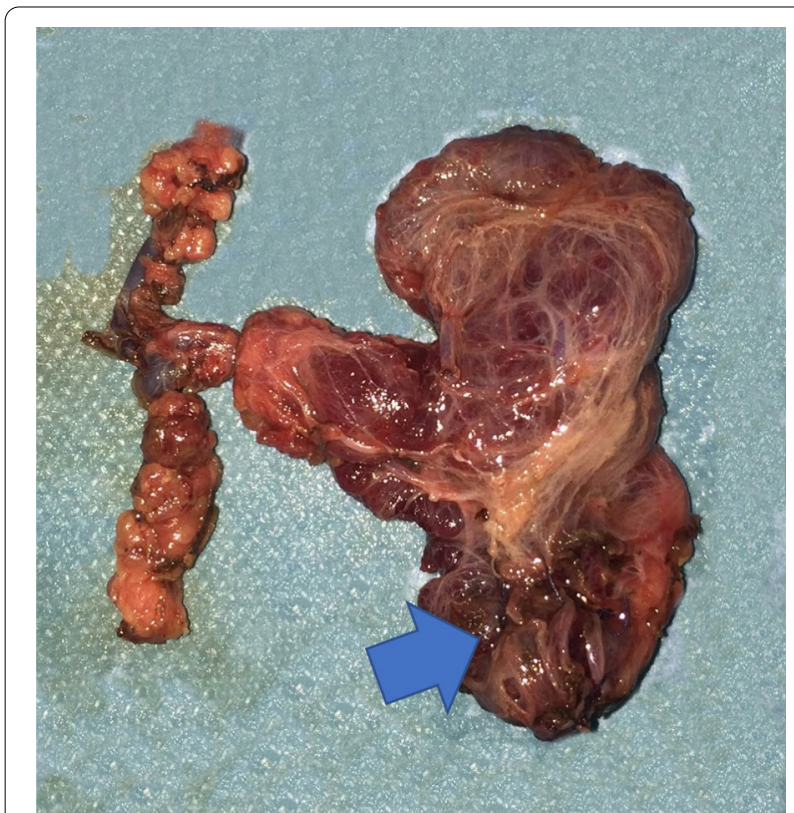

Fig. 3 Right hemithyroidectomy specimen with additional resected nodes of right central compartment (the arrow shows the small bulging at the right lower thyroid pole)

position. These two facts both contributed to the case of PHPT due to the DA that we have already described.

Concerning the size and weight of the DA, De Gregorio et al. found that two types of patterns have been identified: symmetric, in which both adenomas have almost the same size and weight and the asymmetric with one adenoma being heavier and larger than the other [4]. In our patient, the asymmetric pattern was recognized.

We believe that there are two main issues of great importance in our case, based on the global literature. The first is the inability of the preoperative exams to reveal the presence of both adenomas, while only one was detected. This difficulty in locating both adenomas, under ultrasound, sestamibi scan or a combination of them has been also documented in other studies and it is well known that DA are usually responsible for persistent or recurrent PHPT. A meta-analysis with 20,225 cases reported that although the sensitivity of MIBI and ultrasound was $88.44 \%$ and $78.55 \%$ respectively for single gland disease, although for the DA they were up to only $29.25 \%$ and $16.20 \%$ [16]. Furthermore, Haciyanli et al. reported that the accuracy in identifying double adenomas with ultrasound, sestamibi scan and the combination of them was only $40 \%, 30 \%$ and $60 \%$ respectively [17]. In addition, Abboud et al. in their study with 14 patients with DA also reported quite bad results of ultrasound and sestamibi scan detection ability and more precisely they found that the ultrasound of 11 patients failed to detect DA and so did the sestamibi scan in 10 of them [15]. Based on the aforementioned low sensitivity of MIBI and ultrasound to detect DA, we are able to explain why we failed to detect the second smaller adenoma. In our study, we collected imaging data indicative of single gland disease (both thyroid ultrasound and MIBI were positive for inferior right-sided adenoma). Another misleading point was the fact that CaPTHUS score was high (CaPTHUS score $=4$ ), which shows high positive predictive value of around $96 \%$ for single gland disease. Besides, recent studies raise awareness of CaPTHUS score failure to predict single gland disease as a single preoperative modality and therefore ioPTH test was essential $[18,19]$. As a result, we were quite convinced that PHPT was due to single gland disease. Therefore, we did not conduct any other, more advanced imaging tests, such as 4D MRI or F-fluorocholine PET/CT preoperatively, which are found to be more accurate in localizing ectopic or small parathyroid lesions and DA and so we proceeded to focused parathyroidectomy [20,21]. In addition, we failed to find

Table 2 Classifying parathyroid adenomas nomenclature [13]

\begin{tabular}{|c|c|}
\hline Type & Location \\
\hline A & $\begin{array}{l}\text { Adherent to the posterior thyroid parenchyma. Lateral to the recurrent laryngeal nerve compressed within the capsule of the thyroid paren- } \\
\text { chyma. }\end{array}$ \\
\hline B & $\begin{array}{l}\text { A superior gland that has fallen posteriorly into the tracheoesophageal groove and is in the same cross-sectional plane as the superior portion } \\
\text { of the thyroid parenchyma }\end{array}$ \\
\hline C & $\begin{array}{l}\text { Caudal to the thyroid parenchyma, in the tracheoesophageal groove. More inferior than a type B gland on lateral views. At the level of the } \\
\text { inferior pole of the thyroid or inferior to the inferior pole of the thyroid (closer to the clavicle) }\end{array}$ \\
\hline D & $\begin{array}{l}\text { In the midregion of the posterior surface of the thyroid parenchyma, near the junction of the recurrent laryngeal nerve and the inferior thyroid } \\
\text { artery or middle thyroidal vein }\end{array}$ \\
\hline $\mathrm{E}$ & $\begin{array}{l}\text { An inferior gland close to the inferior pole of the thyroid parenchyma, lying in the lateral plane with the thyroid parenchyma and anterior half of } \\
\text { the trachea }\end{array}$ \\
\hline F & An inferior gland that has descended (fallen) into the thyrothymic ligament or superior thymus \\
\hline G & Truly intrathyroidal \\
\hline
\end{tabular}




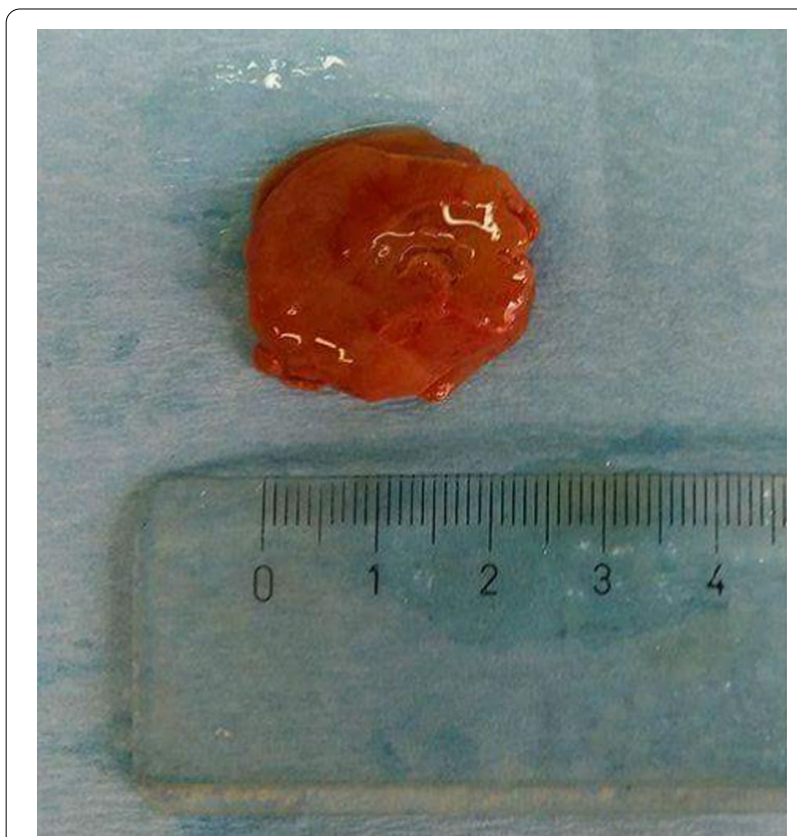

Fig. 4 Excised ectopic parathyroid gland

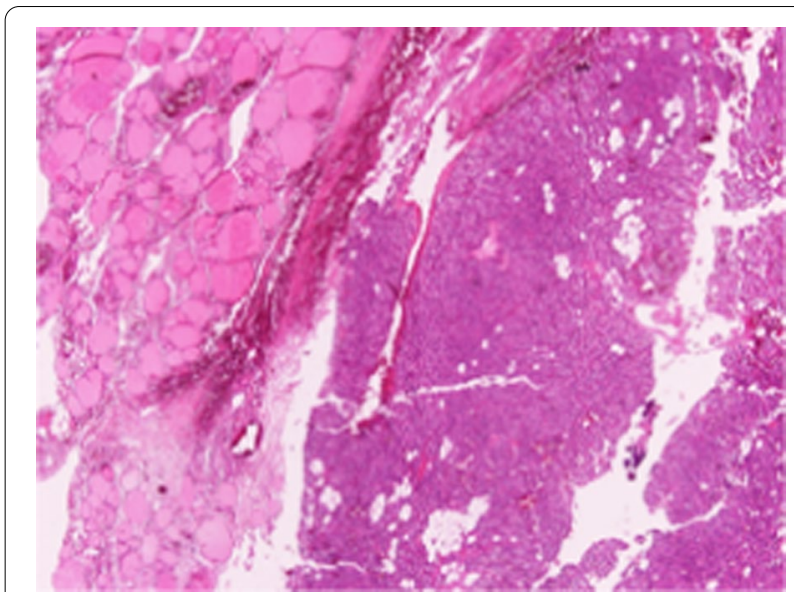

Fig. 5 Pathology image of subcapsular parathyroid adenoma at the lower pole of the right thyroid lobe

the orthotopic right inferior parathyroid adenoma during surgery, which was only revealed in the pathology report. The explanation for this failure was probably the fact that this adenoma (the small one) was under the thyroid capsule and in combination with its small size it was not visible during the examination of the right inferior pole of thyroid gland.

The second confusing point was that after the first adenoma excised, quick intraoperative PTH assay revealed a reduction in PTH levels more than $50 \%$ from the preoperative level, which was indicative of biochemical cure. A reduction of $\mathrm{PTH}$ level more than $35 \%$ is also predictive for single gland disease [22]. Thus, we believed that PHPT derived due to the excised single adenoma until we received the pathology report. The question that has to be answered is why the ioPTH levels dropped beyond the $50 \%$ cutoff point, although a second parathyroid adenoma was present. Kandil et al. in their study reported that intraoperative PTH levels failed to detect the presence of DA in 11 out of 20 PHPT patients (55\%) [5]. In addition, in an American study including 21 patients with DA was found that in 12 patients (57\%) ioPTH levels fell more than $50 \%$, although only the first adenoma was resected and abnormal parathyroid tissue was still present [17]. Similar findings were reported also by Gordon et al., who found that the proportion of false positive results of quick intraoperative $\mathrm{PTH}$ assay as assessment tool for biochemical cure of PHPT during surgery were about 24\% (4 out of 17 patients with DA) [23]. Moreover, in another study, ioPTH showed false positive decline in 9 out of 13 patients after the resection of the first adenoma when the first adenoma had greater weight than the second one [24]. The hypothesis behind this phenomenon is that one of the two parathyroid adenomas, usually the smaller, is suppressed due to the other hyperfunctioning adenoma and therefore, removing the second one results in false positive ioPTH level reduction, similar to single gland disease, as it probably happened in our case [25]. Another less likely theory introduced by Gauger et al. supports that the second adenoma is being devascularized during the process of its exploration or during the excision of the first adenoma and this is the reason why the $\mathrm{PTH}$ produced by that cannot enter the blood circulation and be detected [26]. In our patient we did not dissect the second adenoma at all as we were not aware of its presence. In addition, the prolongation of the operation was due to the small possibility of parathyroid carcinoma that the frozen section reported for the first adenoma.

We need to mention that during our study for this new case of PHPT and having searched the bibliography regarding DA thoroughly, we found that in 2013, Mazeh et al. suggested the Wisconsin Index (WIN) and the WIN nomogram. These were used in order to give an estimation of the likelihood that there is additional hyperfunctioning parathyroid gland during parathyroidectomy for PHPT, irrespectively if this is another adenoma or an overworking gland in the setting of hyperplasia. WIN is defined as the multiplication of preoperative serum calcium by preoperative PTH and the patients are divided into three categories: low (<800), medium (801-1600) 
and high (>1600). The combination of WIN and the weight of the parathyroid gland excised initially, may reveal the existence of an additional pathological gland. For glands weighting the same, the higher the WIN, the greater the possibility of another hyperfunctioning gland. Moreover, the weight of the parathyroid gland is reversely correlated with the chance of a second overworking one [27]. In our case, the WIN was 2292 which means that the possibility of a second hyperfunctioning gland is high. On the other hand, the weight of our heavier adenoma was $3000 \mathrm{mg}$, which decreases the possibility of a second adenoma. So, based on this article we could not estimate the possibility of a second adenoma clearly, because the chance of finding another adenoma correlates positively with the WIN but negatively with the weight based on the nomogram. In addition, a recent study demonstrates that there is a significant failure to cure PHPT in up to $13 \%$, when only WIN is used to predict multi gland disease without ioPTH assay [28]. We are wondering whether it is worth reassessing the validity of the WIN index nomogram in future cohort studies in order to create a new more sophisticated system which will give us the possibility of a second pathologic parathyroid gland, after having calculated the WIN preoperatively, based on the weight of the first adenoma found intraoperatively.

\section{Conclusions}

DA constitute a real unique clinical entity of PHPT and their distribution may vary widely, as in our patient, where the first adenoma was both ectopic and supernumerary and the second one was found under the thyroid capsule of the lower thyroid pole ipsilaterally. Their preoperative localization using the routine imagining tests is still rather disappointing as well as the adoption of ioPTH. In our patient we found a second parathyroid adenoma by chance and we showed for the first time that the possibility of ipsilateral DA of which the one is simultaneously ectopic and supernumerary does exist. For these reasons, we should consider the use of advanced imaging test such as 4D-MRI or F-fluorocholine PET/CT in highly suspicious for DA patients with PHPT. In order to assess these patients, a reevaluation of the suggested "Wisconsin index" nomogram or a similar modality, or even a combination of such a tool with ioPTH should be considered, in order to avoid losing DA. However, at the present time it may be almost impossible to identify preoperatively PHPT patients with DA, (with one adenoma not being localized in the usual imaging methods) who would be major candidate for more advanced imaging tests and the use of such imaging methods should be further investigated with cost-effectiveness cohort studies and randomized clinical trials.

\section{Abbreviations}

DA: Double Adenomas; PHPT: Primary Hyperparathyroidism; PTH: Parathyroid Hormone; iPTH: Intact Parathyroid Hormone; ioPTH: Intraoperative Parathyroid Hormone; MIBI: ${ }^{99 M}$ Tc-Sestamibi scintigraphy; WIN: Wisconsin Index; 4D-CT: Four-Dimensional Computed Tomography; 4D-MRI: Four-Dimensional Magnetic Resonance Imaging.

\section{Acknowledgements}

This paper is dedicated to the memory of Dr. Panagiotis Spyridopoulos who was the director of the Surgical Department and suddenly passed away, before this publication.

\section{Authors' contributions}

GT wrote the manuscript and collected the data. MP and KM wrote and corrected the manuscript for its scientific basis. IP and N-DD collected the data for the study. GC revised the manuscript for grammar and syntax mistakes. KI was one of the consultant surgeons who operated on these cases. SM did the histopathological analysis. PS was the director of the Department of Surgery and the consultant surgeon who provided the cases. All authors read and approved the final manuscript.

\section{Funding}

No additional funding for the execution of the present study was necessary. The investigators executed the present study without any additional reimbursement.

\section{Availability of data and materials}

The data and materials/figures used in the current study are available from the corresponding author on reasonable request.

\section{Ethics approval and consent to participate}

Our case report obtained ethics approval from the ethics committee of our hospital and the patients gave their informed consent to participate.

\section{Informed consent}

Written informed consent was obtained from the patient for publication of this case report and any accompanying images. A copy of the written consents is available for review by the Editor-in-Chief of this journal.

\section{Competing interests}

The authors declare that they have no competing or conflict of interests.

\section{Author details}

${ }^{1} 1$ st Surgical Department, 424 General Military Hospital, Ring Road, 56429 EfkarpiaThessaloniki, Greece. ${ }^{2}$ Pathology Department, 424 General Military Hospital, Thessaloniki, Greece. ${ }^{3}$ Student of Medical, University of Sofia, Sofia, Bulgaria.

Received: 11 November 2019 Accepted: 31 January 2021

Published online: 13 April 2021

\section{References}

1. Kebebew $\mathrm{E}, \mathrm{Clark} \mathrm{OH}$. Parathyroid adenoma, hyperplasia, and carcinoma: localization, technical details of primary neck exploration, and treatment of hypercalcemic crisis. Surg Oncol Clin N Am. 1998;7(4):721-48.

2. Civelek AC, Ozalp E, Donovan P, Udelsman R. Prospective evaluation of delayed technetium-99m sestamibi SPECT scintigraphy for preoperative localization of primary hyperparathyroidism. Surgery. 2002;131(2):149-57.

3. Kaplan EL, Yashiro T, Salti G. Primary hyperparathyroidism in the 1990s. Choice of surgical procedures for this disease. Annals of surgery. 1992;215(4):300-317.

4. De Gregorio L, Lubitz CC, Hodin RA, et al. The truth about double adenomas: incidence, localization, and intraoperative parathyroid hormone. J Am Coll Surg. 2016;222(6):1044-52.

5. Kandil E, Alabbas HH, Bansal A, Islam T, Tufaro AP, Tufano RP. Intraoperative parathyroid hormone assay in patients with primary hyperparathyroidism and double adenoma. Arch Otolaryngol. 2009;135(12):1206-8. 
6. Alhefdhi A, Schneider DF, Sippel R, Chen H. Recurrent and persistence primary hyperparathyroidism occurs more frequently in patients with double adenomas. J Surg Res. 2014;190(1):198-202.

7. Milas M, Wagner K, Easley KA, Siperstein A, Weber CJ. Double adenomas revisited: nonuniform distribution favors enlarged superior parathyroids (fourth pouch disease). Surgery. 2003;134(6):995-1003 (discussion 1003-1004).

8. Phitayakorn R, McHenry CR. Incidence and location of ectopic abnormal parathyroid glands. Am J Surg. 2006;191(3):418-23.

9. Akerstrom G, Malmaeus J, Bergstrom R. Surgical anatomy of human parathyroid glands. Surgery. 1984;95(1):14-21.

10. Wang $C$. The anatomic basis of parathyroid surgery. Ann Surg 1976;183(3):271-5.

11. Henry JF, Defechereux T, Raffaelli M, Lubrano D, lacobone M. Supernumerary ectopic hyperfunctioning parathyroid gland: a potential pitfall in surgery for sporadic primary hyperthyroidism. Ann Chir. 2000;125(3):247-52.

12. Kebebew E, Hwang J, Reiff E, Duh QY, Clark OH. Predictors of single-gland vs multigland parathyroid disease in primary hyperparathyroidism: a simple and accurate scoring model. Arch Surg. 2006:141(8):777-782 (discussion 782).

13. Perrier ND, Edeiken B, Nunez R, et al. A novel nomenclature to classify parathyroid adenomas. World J Surg. 2009;33(3):412-6.

14. Shi Y, Hogue J, Dixit D, Koh J, Olson JA Jr. Functional and genetic studies of isolated cells from parathyroid tumors reveal the complex pathogenesis of parathyroid neoplasia. Proc Natl Acad Sci USA. 2014;111(8):3092-7.

15. Abboud B, Sleilaty G, Helou E, et al. Existence and anatomic distribution of double parathyroid adenoma. Laryngoscope. 2005;115(6):1128-31.

16. Ruda JM, Hollenbeak CS, Stack BC Jr. A systematic review of the diagnosis and treatment of primary hyperparathyroidism from 1995 to 2003. Otolaryngology. 2005;132(3):359-72.

17. Haciyanli M, Lal G, Morita E, Duh Q-Y, Kebebew E, Clark OH. Accuracy of preoperative localization studies and intraoperative parathyroid hormone assay in patients with primary hyperparathyroidism and double adenoma. J Am Coll Surg. 2003;197(5):739-46.

18. Elfenbein DM, Weber S, Schneider DF, Sippel RS, Chen H. CaPTHUS scoring model in primary hyperparathyroidism: can it eliminate the need for ioPTH testing? Ann Surg Oncol. 2015;22(4):1191-5.

19. Mogollon-Gonzalez M, Notario-Fernandez P, Dominguez-Bastante $\mathrm{M}$, et al. The CaPTHUS score as predictor of multiglandular primary hyperparathyroidism in a European population. Langenbeck's Arch Surg. 2016;401(7):937-42.

20. Memeh KO, Palacios JE, Khan R, Guerrero MA. Pre-operative localization of parathyroid adenoma: performance of $4 \mathrm{~d}$ MRI parathyroid protocol. Endocrine Pract. 2019;25(4):361-5.

21. Thanseer N, Bhadada SK, Sood A, et al. Comparative effectiveness of ultrasonography, 99mTc-Sestamibi, and 18F-Fluorocholine PET/CT in detecting parathyroid adenomas in patients with primary hyperparathyroidism. Clin Nucl Med. 2017:42(12):e491-7.

22. Alhefdhi A, Ahmad K, Sippel R, Chen H, Schneider DF. Intraoperative parathyroid hormone levels at 5 min can identify multigland disease. Ann Surg Oncol. 2017;24(3):733-8.

23. Gordon LL, Snyder WH 3rd, Wians F Jr, Nwariaku F, Kim LT. The validity of quick intraoperative parathyroid hormone assay: an evaluation in seventy-two patients based on gross morphologic criteria. Surgery. 1999;126(6):1030-5.

24. Sitges-Serra A, Diaz-Aguirregoitia FJ, de la Quintana A, et al. Weight difference between double parathyroid adenomas is the cause of false-positive IOPTH test after resection of the first lesion. World J Surg. 2010;34(6):1337-42.

25. Zettinig G, Kurtaran A, Prager G, Kaserer K, Dudczak R, Niederle B. "Suppressed" double adenoma-a rare pitfall in minimally invasive parathyroidectomy. Horm Res. 2002;57(1-2):57-60.

26. Gauger PG, Agarwal G, England BG, et al. Intraoperative parathyroid hormone monitoring fails to detect double parathyroid adenomas: a 2-institution experience. Surgery. 2001;130(6):1005-10.

27. Mazeh H, Chen H, Leverson G, Sippel RS. Creation of a "Wisconsin index" nomogram to predict the likelihood of additional hyperfunctioning parathyroid glands during parathyroidectomy. Ann Surg. 2013;257(1):138-41.

28. Edafe O, Collins EE, Ubhi CS, Balasubramanian SP. Current predictive models do not accurately differentiate between single and multi gland disease in primary hyperparathyroidism: a retrospective cohort study of two endocrine surgery units. Ann R Coll Surg Engl. 2018;100(2):140-5.

\section{Publisher's Note}

Springer Nature remains neutral with regard to jurisdictional claims in published maps and institutional affiliations.
Ready to submit your research? Choose BMC and benefit from:

- fast, convenient online submission

- thorough peer review by experienced researchers in your field

- rapid publication on acceptance

- support for research data, including large and complex data types

- gold Open Access which fosters wider collaboration and increased citations

- maximum visibility for your research: over 100M website views per year

At BMC, research is always in progress.

Learn more biomedcentral.com/submissions 